\title{
TECNOLOGIA E EDUCAÇÃO: TRABALHO E FORMAÇÃO DOCENTE
}

\author{
Raquel Goulart Barreto*
}

\begin{abstract}
RESUMO: Este trabalho analisa as construções teóricas e ideológicas relativas à precarização de trabalho e formação docente, tendo em vista os discursos que sustentam as políticas em curso. Para tanto, discute: (1) as tecnologias da informação e da comunicação (TIC) como elo entre "globalização" e trabalho docente; (2) o modo de inserção dessas tecnologias na chamada "sociedade da informação"; (3) a materialização discursiva de tal inserção; (4) as conseqüências da redução das tecnologias a estratégias de educação a distância, destacando o apartheid educacional produzido; (5) a relação-chave entre tecnologias e competências; e (6) as tendências detectadas no contexto atual: a formação baseada em competências, a ênfase nos materiais instrucionais e a desterritorialização da escola, bem como as propostas contra-hegemônicas.
\end{abstract}

Palavras-chave: Sociedade da informação. Tecnologias. Competências. Escola. Trabalho e formação docente.

\section{TECHNOLOGY AND EDUCATION: WORK AND TEACHER'S EDUCATION}

ABSTRACT: This paper aims at analyzing theoretical and ideological constructions regarding teachers' work and preparation, considering the discourse of current policies. In order to achieve this aim, it discusses: (1) technologies as a link between "globalization" and teaching; (2) a discussion on the ways the so-called "information society" approaches information and communication technologies; (3) the discoursive dimension of this approach; (4) the reduction of technologies to distance learning strategies for teaching certification and the sort of apartheid it brings about; (5) the core relation, between technologies and competencies; and (6) the trends identified

* Professora visitante da Faculdade de Educação da Universidade do Estado do Rio de Janeiro (UERJ).E-mail: raquel@uol.com.br. 
in the present context: competency based education, focus on instructional materials and displacement of schools, as well as counterhegemonic proposals.

Key words: Information society. Technologies. Competencies. Schools. Teacher's education and work.

\section{"Globalização" e trabalho docente: no enredo das tecnologias}

( eja a globalização, objeto dos estudos reunidos no dossiê anterior da revista Educação \& Sociedade (87), caracterizada como construção ideológica, seja, como querem alguns, posta como conceito explicativo de uma nova ordem mundial, um aspecto desta realidade não pode ser ignorado: a educação como um todo e o trabalho docente, em especial, estão sendo reconfigurados. Em outras palavras, na perspectiva da "globalização" e do "globalitarismo", termo cunhado por Ramonet (1999) para dar conta da espécie de ditadura do pensamento único que regula a construção ideológica, a escola deve romper com a sua forma histórica presente para fazer frente a novos desafios. A pretensão, neste trabalho, é analisar as determinações (concretas e pressupostas) e os sentidos (hegemônicos e em disputa por hegemonia) dessa reconfiguração, tomando por base os discursos que introduzem e justificam as atuais políticas de formação de professores. ${ }^{2}$

No movimento de reconfiguração de trabalho e formação docente, outro aspecto parece constituir objeto de consenso: a possibilidade da presença das chamadas "novas tecnologias" ou, mais precisamente, das tecnologias da informação e da comunicação (TIC). Essa presença tem sido cada vez mais constante no discurso pedagógico, compreendido tanto como o conjunto das práticas de linguagem desenvolvidas nas situações concretas de ensino quanto as que visam a atingir um nível de explicação para essas mesmas situaçỗes. Em outras palavras, as TIC têm sido apontadas como elemento definidor dos atuais discursos do ensino e sobre o ensino, ainda que prevaleçam nos últimos. Atualmente, nos mais diferentes espaços, os mais diversos textos sobre educação têm, em comum, algum tipo de referência à presença das TIC no ensino. Entretanto, a essa presença têm sido atribuídos sentidos tão diversos que desautorizam leituras singulares. Assim, se aparentemente não há dúvidas acerca de um lugar central atribuído às TIC, também não há consenso quanto à sua delimitação. 
É possível afirmar que, no limite, as TIC estão postas como elemento estruturante de um novo discurso pedagógico, bem como de relações sociais que, por serem inéditas, sustentam neologismos como "cibercultura" (Lévy, 1999). No outro extremo, o que as novas tecnologias sustentam é uma forma de assassinato do mundo real, com a liquidação de todas as referências, em jogos de simulacros e simulação (Baudrillard, 1991). No entremeio, podem constituir novos formatos para as mesmas velhas concepções de ensino e aprendizagem (Moran, 2004), inscritas em um movimento de modernização conservadora, ou, ainda, em condiçõos específicas, instaurar diferenças qualitativas nas práticas pedagógicas (Barreto, 2001; 2002; 2003).

Em síntese, a presença das TIC tem sido investida de sentidos múltiplos, que vão da alternativa de ultrapassagem dos limites postos pelas "velhas tecnologias", representadas principalmente por quadro-de-giz e materiais impressos, à resposta para os mais diversos problemas educacionais ou até mesmo para questões socioeconômico-políticas.

Nas palavras de Mattelart (2002, p. 9), a segunda metade do século XX foi marcada pela "formação de crenças no poder miraculoso das tecnologias informacionais". Mesmo que, em princípio, pareça ingênuo, este último movimento está inscrito em um modo de objetivação das TIC inextricavelmente ligado à concepção de "sociedade da informação", a ser analisada na seção seguinte.

\section{Tecnologias e sociedade da informação}

Depois do "fim da História" prematuramente anunciado por Francis Fukuyama há alguns anos, o que se revela aqui é o engodo do "fim do espaço" de um pequeno planeta suspenso no éter eletrônico de nossos modernos meios de telecomunicação (...). Na falta de um "fim da História", assistimos ao fim da Geografia. (Virilio, 1999, p. 15-17)

Como corolário da "globalização", é importante destacar a chamada revolução científico-tecnológica como extrapolação conceitual indevida, motivada pelo determinismo tecnológico (Leher, 2000). Assim, as tecnologias podem não ser vistas como produçōes histórico-sociais, sendo deslocadas para a origem de mudanças que, por sua vez, sustentam a concepção de "sociedade da informação". 
Tecnologia e educação: trabalho e formação docente

Para caracterizar as simplificaçōes que fundam essa sociedade, recorro à análise empreendida por Mattelart (op. cit., p. 73):

A imprecisão que envolve a noção de informação coroará a de "sociedade da informação". A vontade precoce de legitimar politicamente a realidade hic et nunc desta última justificará os escrúpulos da vigilância epistemológica. A tendência a assimilar a informação a um termo proveniente da estatística (data/dados) e a ver informação somente onde há dispositivos técnicos se acentuará. Assim, instalar-se-á um conceito puramente instrumental de sociedade da informação. Com a atopia social do conceito apagar-se-ão as implicações sociopolíticas de uma expressão que supostamente designa o novo destino do mundo.

Nos termos desta racionalidade instrumental, é possível promover o descentramento da categoria "trabalho" (Antunes, 1999) e até mesmo a sua "eliminação", com o adendo de que isso "não significa o desaparecimento da atividade humana, que pode adquirir a forma das mais diversas ocupaçôes" (Schaff, 1995, p. 42). Também é possível anunciar um novo universalismo, unipolar, com o rearranjo geoeconômico do planeta em torno dos valores da democracia de mercado. É o paradigma tecnoinformacional que, articulado à "globalização", permite a referência à sociedade planetária, a partir da suposição da ausência de um centro identificável, de fronteiras e, ainda, de líderes. Ainda de acordo com Mattelart (op. cit., p. 172):

Os discursos que acompanham a sociedade da informação erigiram em lei o princípio da tabula rasa. Não há nada mais que não seja obsoleto. O determinismo tecnocomercial gera uma modernidade amnésica e dispensa o projeto social. A comunicação sem fim e sem limites institui-se ${ }^{3}$ como herdeira do progresso sem fim e sem limites. (...) A própria noção de complexidade é pervertida e transformada em álibi. Toda atitude contrária a esse positivismo é rapidamente rotulada de tecnofóbica ou antimoderna.

No movimento de cunho "globalitarista", as escolhas são cada vez mais expressas por alternativas e exclusões. Impasses, como o sintetizado por Eco (1977) em Apocalípticos e integrados, adquirem versão atualizada: plugados ou perdidos. Nessa substituição, além da inversão do movimento, as relaçôes entre os termos, antes marcadas por "e", deslizam para a resposta única e o destino idem. Sem mediações. 
Em síntese, é preciso caracterizar a "sociedade da informação" como uma articulação de empreendimentos teóricos, econômicos e políticos. ${ }^{4} \mathrm{E}$, em se tratando dos estudos acerca de tecnologia e educação, é importante distinguir os que partem do seu questionamento daqueles que assumem tal sociedade como pressuposto. Porque é justamente no nível dos pressupostos e implícitos que a ideologia opera no discurso.

\section{Nas tramas do discurso}

Do ponto de vista discursivo, é importante sublinhar e analisar os deslocamentos de sentido que têm marcado as práticas de linguagem, como manifestações das novas concepções hegemônicas. O primeiro deles, na medida em que é mais geral, diz respeito ao modo pelo qual as desigualdades e diferenças estão sendo tratadas. As alusões "globalizantes" deixam de incluir expressões como: Primeiro e Terceiro Mundo; países centrais e países periféricos etc. As referências passam a ser os países do Norte e do Sul, como se as questôes que os distinguem pudessem ser reduzidas a coordenadas geográficas.

Entre as novas tendências discursivas, merece destaque a "relexicalização" (Fairclough, 2001), que consiste na utilização de termos historicamente associados a outras atividades e relaçôes, como estratégia de legitimação de deslocamentos de sentido, na maioria das vezes inscritos no movimento de "comodificação" (idem, ibid., p. 255): "Processo pelo qual os domínios e as instituiçôes sociais, cujo propósito não seja produzir mercadorias no sentido econômico restrito de artigos para venda, vêm não obstante a ser organizados e definidos em termos de produção, distribuição e consumo de mercadorias". 5

No campo educacional, há algum tempo, têm sido recorrentes termos como: "consumidores", "clientes", "pacotes", "produtos" etc. Atualmente, é possível verificar que tal recorrência funcionou na preparação do cenário para o deslocamento da educação mesma para o setor de serviços, capitaneada pela Organização Mundial do Comércio (OMC), nos termos da sua regulamentação no GATS. ${ }^{6}$

Os documentos concernentes à formação de professores, como as Diretrizes Curriculares Nacionais para a Formação de Professores da Educação Básica, em nível superior, curso de licenciatura e de graduação plena, ${ }^{7}$ explicitam a aposta na reconfiguração do trabalho, tendo em vista a "sociedade da informação": 
Com relação ao mundo do trabalho, sabe-se que um dos fatores de produção decisivos passa a ser o conhecimento e o controle do meio técnico-científico-informacional, reorganizando o poder advindo da posse do capital, da terra ou da mão-de-obra. (Idem, ibid., p. 9)

No que diz respeito ao trabalho docente propriamente dito, o "abandono da categoria trabalho pelas categorias da prática, prática reflexiva" (Freitas, 2003, p. 1.096) tem sustentado a utilização de expressões como "atividades" e "tarefas docentes". É a materialização discursiva do esvaziamento desse trabalho, com a restrição do professor à escolha do material didático a ser usado nas aulas, durante as quais lhe cabe controlar o tempo de contato dos alunos com os referidos materiais, concebidos como mercadorias cada vez mais prontas para serem consumidas (Barreto, 2002).

A própria designação "professor" tem cedido espaço a "facilitador", "animador", "tutor", "monitor" etc. E monitor, nos seus múltiplos sentidos, pode ser uma imagem-síntese da precarização do trabalho docente. Consultando os significados dicionarizados da palavra, ${ }^{8}$ é possível identificar: (1) aquele que dá conselhos, liçôes, que admoesta; (2) aluno que auxilia o professor no ensino de uma matéria, em geral na aplicação de exercícios, na elucidação de dúvidas etc., fora das aulas regulares; (3) instrumento que controla o funcionamento de um equipamento ou sistema; (4) aparelho receptor utilizado para se supervisionar a qualidade do vídeo e/ou áudio durante uma transmissão ou gravação; e (5) dispositivo de saída de dados, no qual se visualizam as informações apresentadas por um computador; a tela do computador.

Tomando o primeiro e o segundo sentidos, se o professor é posto como monitor, quem ocupa a posição de professor? Uma resposta explícita pode ser encontrada no site da Secretaria de Educação a Distância, do MEC (www.mec.gov.br/seed/linhas.shtm):

As linhas de ação da Secretaria de Educação a Distância fundamentam-se na existência de um sistema tecnológico - cada vez mais barato, acessível e de manuseio mais simples - capaz de:

- trazer para a escola um enorme potencial didático-pedagógico;

- ampliar oportunidades onde os recursos são escassos;

- familiarizar o cidadão com a tecnologia que está em seu cotidiano; 
- dar respostas flexíveis e personalizadas para pessoas que exigem diversidade maior de tipos de educação, informação e treinamento;

- oferecer meios de atualizar rapidamente o conhecimento;

- estender os espaços educacionais;

- e motivar os profissionais e alunos para aprenderem continuamente, em qualquer estágio de suas vidas.

Para além dos semânticos, está posto o deslocamento sintático radical: é o sistema tecnológico, com as qualificações registradas (preço, acessibilidade e simplicidade de manuseio), ocupando a posição de sujeito capaz de desenvolver ações estratégicas. Não por acaso, a redução das tecnologias a propostas de educação a distância (EAD) também está marcada na própria nomeação da secretaria criada para coordenar as açōes ministeriais com relação às TIC.

Cabe acrescentar, ainda, que, já no Dicionário Houaiss, o monitor é identificado à "pessoa que organiza, administra e orienta turmas de telealunos, promovendo reuniōes, estudos em grupo, responsabilizando-se pelas matrículas, pelos testes preparatórios etc.”. Em outras palavras, este sentido está não apenas legitimado, mas sedimentado, documentado em uma obra de referência.

O terceiro e o quarto sentidos apontam para um instrumento que visa ao controle, termo recorrente na atual "comodificação" do discurso pedagógico. Está presente nos programas oficiais e nas pesquisas neles centradas (André, 2004) também como regulação ou gerenciamento. É o que pode ser verificado, por exemplo, nas Diretrizes Curriculares já citadas, quando da explicitação da tarefa mais importante a ser desempenhada pelos professores:

Urge, pois, inserir as diversas tecnologias da informação e das comunicações no desenvolvimento dos cursos de formação de professores, preparando-os para a finalidade mais nobre da educação escolar: a gestão e a definição de referências éticas, científicas e estéticas para a troca e negociação de sentido, que acontece especialmente na interação e no trabalho escolar coletivo. Gerir e referir o sentido será o mais importante e o professor precisará aprender a fazề-lo em ambientes reais e virtuais. (André, 2004, p. 25; grifos meus) 
O trecho acima é elucidativo de uma das aparentes contradições que fundam as relações entre tecnologias e trabalho docente. De um lado, a abertura para o múltiplo, e, de outro, a legitimação do supostamente singular. O trabalho é, ao mesmo tempo (supostamente), expandido e reduzido. $\mathrm{Ou}$, em termos mais abrangentes, flexibilização e democratização (supostas) convivem com monopólio e controle. ${ }^{9}$ Afinal, monitorar significa vigiar, verificar (algo), visando a determinado fim. No novo contexto, objetificação e racionalidade instrumental, articuladas, também funcionam para o deslocamento da discussão acerca dos fins determinados, nas suas múltiplas dimensões.

O quinto sentido aqui listado dá conta da face mais visível dos deslocamentos operados: a da visualização das informações em dispositivo de saída de dados. É o núcleo da analogia: mostrar o que os processadores e as interfaces permitem. Ligar os aparelhos nas tomadas e solucionar as questôes previstas. Tem sido esta a tônica dos treinamentos e das capacitações promovidos pelos programas em nível nacional, como TV Escola e PROINFO. ${ }^{10} \mathrm{Em}$ nível estadual, até mesmo na educação básica, como no caso do Ceará e do Maranhão, as teleaulas podem configurar substituição tecnológica radical.

Recusar a analogia e reverter esse quadro requer a formação de professores no/pelo trabalho com as TIC e requer que, portanto, não lhes atribua o estatuto de meros instrumentos para quaisquer finalidades. São necessários professores que também não sejam monitorados pelas TIC. Afinal, vale lembrar que o monitor, tecnicamente, é periférico.

\section{As TIC para a EAD}

Os organismos internacionais têm forçado, por meio do estabelecimento de "condicionalidades" para a concessão de créditos e a aplicação de sanções pelo seu descumprimento (Fonseca, 1998, p. 41), a incorporação das TIC como elemento central de qualquer política educacional atenta às transformações engendradas pela chamada revolução científico-tecnológica e às necessidades da economia. Nas palavras de Barreto \& Leher (2003, p. 39):

"Um admirável mundo novo emerge com a globalização e com a revolução tecnológica que a impulsiona rumo ao futuro virtuoso". (...) A partir dessa premissa, organismos internacionais e governos fazem ecoar uma 
mesma proposição: é preciso reformar de alto a baixo a educação, tornando-a mais flexível e capaz de aumentar a competitividade das nações, únicos meios de obter o passaporte para o seleto grupo de países capazes de uma integração competitiva no mundo globalizado.

Nesse movimento, tem sido anunciado um novo paradigma educacional. $\mathrm{O}$ anúncio é recorrente no site do MEC, cuja formulação, vale insistir, levou o discurso dos organismos internacionais às últimas conseqüências, posicionando as tecnologias no lugar dos sujeitos. Esse paradigma é constituído pela substituição tecnológica e pela racionalidade instrumental, está inscrito na "flexibilização", especialmente na precarização do trabalho docente, sendo coerente com a lógica do mercado: quanto maior a presença da tecnologia, menor a necessidade do trabalho humano. Em outras palavras, prevê cada vez menos professores e mais alunos, sob a alegação de que o desempenho dos últimos depende menos da formação dos primeiros e mais dos materiais utilizados.

A rigor, o discurso do MEC opera duas inversôes: substitui a lógica da produção pela da circulação e a lógica do trabalho pela da comunicação, na crença de que, "sem alterar o processo de formação de professores do ensino básico e sem alterar seus salários aviltantes, tudo irá bem na educação desde que haja televisões e computadores nas escolas" (Chaui, 1999, p. 33). Ademais, no Brasil, há muito poucos kits tecnológicos instalados, conforme atestam os dados abaixo: ${ }^{11}$

\section{Tabela 1}

Kits tecnológicos nas escolas brasileiras

\begin{tabular}{|l|c|c|c|}
\hline \multicolumn{3}{|c|}{ Escolas da Educação Básica - Brasil - 2003 } \\
\hline \multicolumn{1}{|c|}{ Regiōes } & Total & $\begin{array}{c}\text { Com antena } \\
\text { parabólica }\end{array}$ & $\begin{array}{c}\text { Com o kit completo } \\
\text { (parabólica, televisão e videocassete) }\end{array}$ \\
\hline Norte & 26.366 & 4.692 & 4.109 \\
Nordeste & 91.072 & 18.090 & 15.990 \\
Sudeste & 57.098 & 22.639 & 21.911 \\
Sul & 27.040 & 11.385 & 10.956 \\
Centro-Oeste & 10.349 & 4.609 & 4.404 \\
Brasil & 211.933 & 61.415 & 57.370 \\
\hline
\end{tabular}

Fonte: MEC/INEP. 
Nas propostas dos organismos internacionais, "o acesso via Internet ao 'saber universal', que necessariamente terá a sua fonte nos monopólios de saber já existentes, resolveria o problema não apenas da fratura digital mas também o da fratura social" (Mattelart, 2002, p. 173). Nestes termos, é formulada a proposta de "tecnologias para todos", como superação do chamado "divisor digital". Em contrapartida, como afirma Leher (1997, p. 138), o próprio Banco Mundial, ao assinalar que a utilização das tecnologias é o "instrumento privilegiado para inserir os países no fluxo hegemônico do Tempo", também reconhece a inviabilidade de que os países caracterizados pelos tempos lentos (em desenvolvimento, periféricos, do Sul) venham a ser inseridos no ritmo acelerado dos países centrais (do Norte).

Desse modo, ao passo que são apregoadas novas possibilidades, como a superação do divisor digital, é instituída, com base na sua própria ressignificação, uma espécie de apartheid educacional em escala planetária. Ao passo que o discurso trata da democratização do acesso, as práticas sociais evidenciam que essa espécie de linha divisória entre os incluídos e os excluídos não diz respeito a acesso ou ausência de acesso, mas aos modos como ele é produzido e aos sentidos de que é investido.

À guisa de ilustração, segue a imagem de uma capa de TechKnowLogia, ${ }^{12}$ publicação on-line vinculada a vários organismos internacionais.

\section{Ilustração 1}

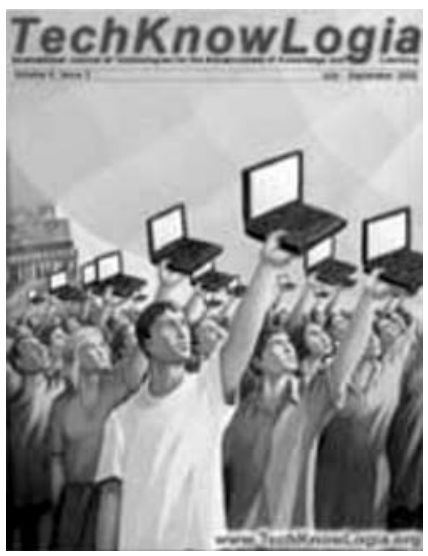


Nessa imagem, é importante destacar a multidão de rostos muito semelhantes, como que brandindo, em gesto idêntico, laptops iguais. As diferenças parecem ter sido pasteurizadas. Tudo parece achatado. As telas em suas mãos estão igualmente em branco, como se, a despeito de estarem ligadas, permanecessem apagadas. As mãos totalmente erguidas podem sugerir que as pessoas estejam portando antenas para captar o que lhes for enviado, já que os monitores não permitem visualizar o que quer que seja, para além da luz branca. É a multidão que permanece sem acesso real à informação que possa fazer diferença.

Sem entrar no mérito do possível engano ou de uma espécie de ato falho, é importante acrescentar que a citada revista evidencia, nos seus diversos números, uma distinção entre as propostas de utilização das TIC em países do Norte e do Sul. Nos primeiros, têm o sentido de agregar novas possibilidades aos processos pedagógicos. Nos últimos, configuram estratégias de substituição tecnológica, nas quais a ênfase é posta na formação de professores a distância (EAD), identificada, por sua vez, à certificação em massa.

As simplificações e os deslocamentos que têm caracterizado as propostas oficiais de EAD expressam o esvaziamento da formação de professores, progressivamente deslocada para "capacitação em serviço" ou até mesmo "reciclagem", visto que a formação inicial "presencial" não conta com o financiamento internacional alocado nas TIC para a EAD, não garantindo sequer o direito de acesso às tecnologias. Já nos braços virtuais das universidades públicas, ${ }^{13}$ na atual formação cindida, as TIC estão no centro, as considerações pedagógicas nas margens e as questôes de fundo obliteradas.

Essa formação esvaziada também tem sido marcada por pelo menos duas cisões importantes. A primeira delas diz respeito à dicotomização: formação inicial $X$ formação continuada, em nova feição. Se, até os anos de 1990, o termo "formação" parecia remeter apenas à inicial, agora passa a apontar para a continuada, destinação de quase todos os investimentos nacionais e internacionais. Como afirma Torres (1998, p. 176): "A questão mesma da formação inicial está se diluindo, desaparecendo". Ao mesmo tempo, a formação continuada fica restrita a "capacitação", "treinamento" e "reciclagem".

A segunda cisão corresponde à modalidade: presencial $\mathrm{X}$ a distância. Na modalidade presencial, as políticas em curso apontam para 
outra cisão: ensino e pesquisa, ${ }^{14}$ desqualificando o chamado "modelo europeu de universidade", constituído pela indissociabilidade de ensino, pesquisa e extensão. E, no que tange às TIC, a ausência de investimentos específicos e a dotação orçamentária minguada sequer garantem o direito de acesso. Enquanto isso, na formação a distância, entre simplificações como a mera transposição de aulas para os novos suportes, o acesso às TIC fica restrito à condição de usuários ou consumidores, até mesmo esta podendo ser perdida ao final do processo, em face das condiçóes materiais de existência dos sujeitos em formação e da remuneração que percebem quando formados.

$\mathrm{Na}$ base dessas cisões ${ }^{15}$ está um modo de objetivação das TIC que não passa pela análise das condições da sua inserção nos processos pedagógicos como um todo. Assim, por exemplo, em iniciativas que pretendem potencializar os processos presenciais pelo recurso às TIC, como nos cursos chamados "semipresenciais", não há um redimensionamento da carga horária e da remuneração dos professores para incluir o tempo despendido na leitura dos textos dos alunos nos fóruns ou em listas de discussão, na respostas a e-mails etc. $\mathrm{O}$ que o recurso às TIC, na perspectiva da substituição tecnológica, viabiliza é justamente o oposto: processos de subcontratação, de trabalho em tempo parcial e de terceirização.

Em outras palavras, ficam de fora as condições necessárias à apropriação educacional das TIC, já que nenhum dos grupos é formado no trabalho com elas, o que implica superar a sedução por atributos supostamente intrínsecos, como atratividade, não privilegiando apenas a interação dos sujeitos com os materiais. O horizonte precisa ser a interação maior: a discussão (das informações coletadas e dos processos vividos) para o confronto dos diferentes percursos (individuais), visando à produção (coletiva) de sínteses integradoras que extrapolem conteúdos específicos previstos.

Esse horizonte, por sua vez, remete à outra superação: a da defesa do ensino presencial centrada apenas nas relaçóes afetivas. O que está em jogo não são simplesmente os afetos possíveis, mas a "objetividade social compartilhada pelos atores das práticas sociais na instituição escolar" (Silva Júnior, 2003, p. 84): o exercício da reflexão a partir das condições concretas da sua realização, visando à produção de alternativas teóricometodológicas para a aproximação dos objetos.

A proposta de formação inicial a distância, sob o mote da superação das distâncias geográficas e das desigualdades sociais, tem filiações 
inegáveis. Do ponto de vista político, está inscrita no conjunto das reformas estruturais, ainda que o aporte tecnológico seja incipiente, como demonstrado na Tabela 1, e ainda que, do ponto de vista técnico, não exista o acúmulo suposto em várias manifestações oficiais, como: "As metas da Secretaria de Educação a Distância são, pois, levar para a escola pública toda a contribuição que os métodos, técnicas e tecnologias de educação a distância podem prestar à construção de um novo paradigma para a educação brasileira”.

O novo paradigma assume a redução das tecnologias a ferramentas de ensino a distância, excluindo justamente os modos da sua apropriação na formação e no trabalho docente. Entretanto, a identificação das TIC ao seu fundamento também constitui uma espécie de metonímia. É preciso reconhecer que elas são importantes porque funcionam como um dos vértices da triangulação que permite ao Estado ser mínimo, no que diz respeito a investimento, e máximo, quando se trata do gerenciamento da educação: currículo centralizado (parâmetros e diretrizes curriculares), uso intensivo de tecnologias (programas específicos ${ }^{16}$ ) e avaliação unificada externa (SAEB, ENEM, ENC e, mais ainda, SINAES).

Sem dúvida, nessa triangulação, as TIC funcionam como um elo, promovendo a ligação entre as pontas e até mesmo a quebra da unidade ensino-aprendizagem, tornando possível um discurso que destaca apenas o segundo elemento do par, ao apontar para a aprendizagem independente do ensino. Mas só podem fazê-lo a partir de uma concepção específica de conhecimento, conteúdo e formação, fundada na noção de competência.

\section{A relação-chave: TIC e competências}

Para demonstrar que o núcleo sólido da proposta de incorporação das TIC são as competências, é importante recorrer à formulação de Labarca (1995), então consultor da CEPAL (UNESCO), ${ }^{17}$ que parte da seguinte premissa: a produtividade dos sistemas educacionais é baixa, em razão do uso intensivo do recurso humano e do seu corporativismo, que protege o "monopólio docente na transmissão do conhecimento" (idem, ibid., p. 174). Prosseguindo em direção ao expurgo do professor, posto como tecnologia cara e pouco eficiente, o autor é bastante explícito com relação aos encaminhamentos (idem, ibid., p. 175-176): 
Os docentes deixam de ser os principais depositários do conhecimento e passam a ser consultores metodológicos e animadores de grupos de trabalho. Esta estratégia obriga a reformular os objetivos da educação. $O$ desenvolvimento de competências-chave (...) substitui a sólida formação disciplinar até então visada. O uso de novas tecnologias educativas leva ao apagamento dos limites entre as disciplinas, redefinindo, ao mesmo tempo, a função, a formação e o aperfeiçoamento dos docentes. (Grifos meus)

No mesmo artigo, o autor deixa claro que não mudam substantivamente as propostas dos organismos internacionais para os contextos em que o acesso às TIC é mais difícil. O que é redimensionado são as tecnologias mesmas, sendo defendido o uso de materiais impressos, produzidos em nível central e distribuídos aos professores, desde que acompanhados de algum tipo de variação em torno de manual de instruçôes.

Se, de um lado, a noção de competência envolve dificuldades teóricas (Dias \& Lopes, 2003), são muito claros os pressupostos assumidos nas propostas de formação baseada em competências: (1) o ensino pode ser decomposto em habilidades e competências básicas; e (2) a formação dos professores organizada a partir dessas habilidades e competências corresponde ao desempenho docente "desejável". Em outras palavras, trata-se da suposição de que a totalidade (trabalho docente) seja equivalente à soma das partes. O reducionismo é inevitável, ao passo que a sofisticação pode ser maior, considerando os novos recursos tecnológicos que podem co-operar com as competências. É na articulação do reducionismo à sofisticação que está fundada a estratégia de substituição tecnológica.

Nestes termos, é possível sustentar a triangulação descrita na seção anterior. É possível intensificar o uso da força de trabalho por meio de uma suposta revolução tecnológica e até produzir evidências da eficiência dos meios para os fins estabelecidos, uma vez que diretrizes e parâmetros definem as competências a serem desenvolvidas por intermédio dos materiais produzidos para tanto, sendo estas avaliadas ao final do processo.

Evidentemente, essa triangulação não pode ser concretizada de modo automático. A proposta de controle esbarra em obstáculos políticos e técnicos que não são facilmente contornáveis. Na tentativa de viabilizá-la, algumas providências adicionais têm de ser tomadas. Uma das principais diz respeito à implementação de sistemas de avaliação e certificação por competência profissional, ora assumida pelo INEP. ${ }^{18}$ 
Em síntese, atribuir o conjunto das questôes atuais relativas ao trabalho docente à presença, ou mesmo a um modo de incorporação, das TIC também contribui para obliterar a análise política das tendências atuais.

\section{Tendências atuais}

As formulações da virada do século, ainda que em novas bases, não deixam de constituir uma retomada das propostas produzidas na década de 1970. "Mantém-se aqui sua característica fundamental: uma análise da educação desgarrada de seus determinantes históricos e sociais" (Freitas, 1992, p. 98). Portanto, assumem cunho marcadamente neotecnicista, do gerenciamento da educação a partir de competências (Houston, 1974), passando pela aposta nos materiais ditos "autoinstrucionais", até as alternativas de uma sociedade sem escolas (Illich, 1973).

O que há de novo são discursos muito mais elaborados, sob os mais diversos pontos de vista, assim como mais ágeis na conquista de materialidade mais espessa. Assim, nas relações entre discurso e mudança social, a "comodificação" do discurso educacional ultrapassa os limites da dimensão simbólica e instaura, concretamente, o lugar da sobremercantilização da educação: os cursos como pacotes, a prestação de serviços educacionais, o gerenciamento da OMC. Ou, por outro ângulo, o campo da ideologia teria sido reconfigurado para promover as condições mais favoráveis às mudanças pretendidas.

De qualquer modo, as relações entre discurso e mudança social precisam ser objeto de atenta análise política, com o fim dar conta de novos clichês (como "pense globalmente e aja localmente") que, circulando, contribuem para a produção de um imaginário o qual faz com que uma interpretação particular apareça como sendo a necessária, ao sustentar a legitimação e a fixação de sentidos hegemônicos. Vale lembrar que, do ponto de vista discursivo, ideologia corresponde a hegemonia de sentido.

O sentido hegemônico das TIC aponta para o primado da dimensão técnica, apagando as questôes de fundo. Em se tratando da sua incorporação educacional, parece não haver espaço para a análise dos seus modos e sentidos. Na perspectiva maniqueísta de "plugados ou perdi- 
dos", quaisquer objeções podem ser alvo da desqualificação que marca o segundo grupo. Enquanto isso, no primeiro, as discussóes podem ser travadas a partir de questões como as diferenças entre aprendizagem cooperativa e colaborativa, ou entre construtivismo e construcionismo (Papert, 1993), nos limites da esfera dita pedagógica, sem remeter às suas dimensões econômicas, políticas e sociais.

Neste contexto, é importante verificar a afirmação de um "novo paradigma", recorrente no site do MEC, ou paradigma emergente, em geral associado ao afastamento das objetivações supostamente marcadas pela simplicidade, em direção à complexidade (Morin, 1998). É inegável a hegemonia do movimento de virtualização do ensino, na perspectiva de e-learning, cuja tradução mais comum tem sido "educação a distância via Internet": uma forma de aprendizagem em que a mediação tecnológica é destacada, nos mais diversos "ambientes de aprendizagem".

Mesmo sem entrar no mérito da polissemia desta expressão, é importante pontuar que ela deixa de contemplar o ensino, concentrando-se no segundo elemento do par: a aprendizagem. É quebrada a unidade ensino-aprendizagem, que tem dado sustentação aos mais diversos estudos acerca das práticas educativas, supondo a aprendizagem sem ensino ou, ainda, o ensino inteiramente identificado aos materiais que sustentam as alternativas de e-learning. Em qualquer das hipóteses, essa quebra não pode ser desvinculada do "novo lugar" do professor, na condição de profissional do ensino.

Ainda quanto aos clichês em circulação, é possível verificar um deslocamento significativo de "não se aprende apenas na escola" para "não se aprende na escola", na medida em que remete à tendência de desterritorialização da escola. Não apenas toda a ênfase está sendo posta nos ambientes de aprendizagem, mas os textos já contemplam "educações" diversas, materializadas nas expressões "educação acadêmica" e "educação corporativa”.

Retomando o ponto de partida deste conjunto de reflexóes, é possível afirmar que a desterritorialização proposta não pode ser pensada fora dos parâmetros mercadológicos e do pressuposto de que a escola deva romper com a sua forma histórica presente para fazer frente aos desafios da "globalização". Rejeitando esta lógica, o desafio maior é fazer frente à tentativa de apagamento dos determinantes históricos e sociais da escola. Nas palavras de Alves (2004, p. 218): 
Discutir o papel específico, hoje, da escola para os vários grupos, suas múltiplas diferenças e distâncias, torna-se neste contexto algo premente (...) a escola é um espaço único e especial (...) um espaçotempo de juntar pessoas (...) é preciso recuperar o espaço do saber, que nada tem a ver com o lugar de uma certa competência técnica. (Grifos da autora)

O que está em jogo não é só o discurso competente: "Aquele que pode ser proferido, ouvido e aceito como verdadeiro ou autorizado (estes termos agora se equivalem) porque perdeu os laços com o lugar e o tempo de sua origem" (Chaui, 1989, p. 7). É, entre outras questóes, a redução das TIC à EAD, como forma material da "comodificação". São os embates contemporâneos entre a proposta de educação como mercadoria e a sua defesa como direito e prática emancipatória.

\section{Recebido e aprovado em setembro de 2004.}

\section{Notas}

1. Considerando os limites deste artigo, remeto a Limoeiro-Cardoso (1999) e a Hirst \& Thompson (1998), para análise circunstanciada de "globalização", respectivamente, como ideologia e como mito.

2. Este trabalho está reportado a duas pesquisas: (1) Tecnologias da Informação e da Comunicação e Educação a Distância: o discurso do MEC (2001-2003/CNPQ e UFRJ); e (2) As tecnologias da informação e da comunicação nas políticas de formação de professores: os sentidos da reconfiguração de trabalho-formação docente (2004-2007/CNPQ e UERJ).

3. Do ponto de vista sintático, considerando o funcionamento da partícula apassivadora no apagamento do agente e do processo, é importante substituir "institui-se" por "é instituída".

4. Lima (2004) aborda esta questão, considerando a atuação de redes como a do Observatório Internacional das Reformas Universitárias (Rede oRUs) e da Associação para um Mundo Complexo da Fundação Charles Leopoldo Mayer para o Progresso do Homem (Rede FPH), ambas presididas pelo ideólogo do "novo paradigma da complexidade": Edgar Morin. Leher (2004), disponível em: http://www.andes.org.br/reforma_universitaria_ brasil_banco_mundial.pdf, também analisa as condições em que foi produzida a intervenção da Rede ORUS no encaminhamento da (contra) reforma universitária no Governo Lula.

5. Outra tradução para esse processo, centrado na noção de commodities, é apresentada por Blikstein \& Zuffo (2003): "comoditização", com base em David Noble.

6. A propósito, ver: www.unesco.org/education/studyingabroad/highlights/global_forum/ gats_he/us.pdf.

7. Cf. Parecer CNE/CP n. 009/2001, disponível em: http://www.mec.gov.br/cne/pdf/009.pdf, compreendendo 70 páginas, nas quais são explicitados os argumentos que sustentam a versão sintética, formatada como texto legal, aprovada em fevereiro de 2002. Disponível em: http://www.mec.gov.br/cne/pdf/CP012002.pdf. 
8. Neste ponto, vale lembrar Vygotsky (1991, p. 125): "O significado dicionarizado de uma palavra nada mais é do que uma pedra no edifício do sentido, não passa de uma potencialidade que se realiza de formas diversas na fala".

9. Mészáros (2003, p. 51) afirma: "Para mencionar apenas um caso, a Microsoft desfruta de uma posição de quase absoluto monopólio mundial, por meio da qual seus programas geram conseqüências pesadas também para a aquisição do equipamento mais adequado. Mas além dessa questão, descobriu-se há pouco um código secreto embutido nos programas da Microsoft, que permite aos serviços militares e de inteligência dos Estados Unidos espionar qualquer pessoa no mundo que seja usuária do Windows e da Internet".

10. Ver, especialmente, os textos de Magalhães ("Programa TV Escola: o dito e o visto") e Cysneiros ("Programa Nacional de Informática na Educação: novas tecnologias, velhas estruturas"), no livro organizado por Barreto (2001).

11. Neste ponto, cabem duas observaçôes: a primeira diz respeito à opção pelo sinal codificado e a segunda ao número sempre maior de antenas parabólicas instaladas, mesmo que não haja aparelhos de TV nas escolas.

12. TechKnowLogia: International Journal of Technologies for the Advancement of Knowledge and Learning. Technologies for All: Issues of Equity (jul.-sep. 2002) <www.techKnowLogia.org>. Published by Knowledge Enterprise, Inc. Issue Co-Sponsored by Academy for Educational Development (AED /USAID).

13. Ao passo que as universidades privadas têm tido presença cada vez maior na formação inicial presencial, nos cursos de graduação a distância, marcados por crescimento exponencial (as matrículas passaram de $1.682 \mathrm{em} 2000$ para 40.714 em 2002), as universidades públicas concentram a maioria das iniciativas.

14. A propósito, ver o capítulo intitulado "Condições de produção da formação docente" (Barreto, 2002).

15. Em correspondência enviada por um grupo de alunos de uma universidade estadual localizada no sul do Brasil, a propósito de estabelecer interlocução acerca de livro por mim organizado (2001), uma queixa reiterada dá conta de outra cisão, no interior dos cursos presenciais: os mantidos exclusivamente pela universidade, contando com recursos cada vez mais parcos, e os resultantes de convênios com órgãos ou entidades, nos quais a presença das TIC é garantida pelos aportes financeiros destes últimos.

16. TV Escola, Programa Nacional de Informática na Educação, Programa de Formação de Professores em Exercício, Programa de Apoio à Pesquisa em Educação a Distância e Rádio Escola.

17. Comisión Económica para América Latina y el Caribe.

18. Informativo do INEP: "O INEP está promovendo, nos dias 8 e 9 de setembro de 2004, no San Marco Hotel, em Brasília, o Encontro Internacional de Certificação por Competência Profissional. O evento reúne diversos segmentos nacionais envolvidos na discussão do tema, que contarão com a contribuição de especialistas internacionais, os quais apresentarão modelos e estruturas desses sistemas em seus países”.

\section{Referências bibliográficas}

\section{ALVES, N. Imagens de tecnologias nos cotidianos das escolas, discu- tindo a relação "localuniversal". In: RomAnOwski et al. (Org.). Conhe-}


cimento local e conhecimento universal: diversidade, mídias e tecnologias na educação. Curitiba: Champagnat, 2004. p. 215-228.

ANDRÉ, M. Uma pesquisa com os professores para avaliar a formação de professores. In: Romanowski et al. (Org.). Conhecimento local e conhecimento universal: pesquisa, didática e ação docente. Curitiba: Champagnat, 2004. p. 205-218.

ANTUNES, R. Os sentidos do trabalho: ensaio sobre a afirmação e a negação do trabalho. São Paulo: Boitempo Editorial, 1999.

BARRETO, R.G. (Org.). Tecnologias educacionais e educação a distância: avaliando políticas e práticas. Rio de Janeiro: Quartet, 2001.

BARRETO, R.G. Formação de professores, tecnologias e linguagens: mapeando novos e velhos (des)encontros. São Paulo: Loyola, 2002.

BARRETO, R.G. As tecnologias na formação de professores: o discurso do MEC. Educação \& Pesquisa, n. 30, jul./dez. 2003. p. 271-286.

BARRETO, R.G.; LEHER, R. Trabalho docente e as reformas neoliberais. In: Oliveira, D.A. (Org.). Reformas educacionais na América Latina e os trabalhadores docentes. Belo Horizonte: Autêntica, 2003. p. 39-60.

BAUDRILLARD, J. Simulacros e simulação. Lisboa: Relógio d'Água, 1991.

BLIKSTEIN, P.; ZUFFO, M.K. As sereias do ensino eletrônico. In: SILVA, M. (Org.). Educação online. São Paulo: Loyola, 2003. p. 23-38.

CHAUI, M. Ideologia neoliberal e universidade. In: Oliveira, F.; PaOli, M.C. (Org.). Os sentidos da democracia: políticas do dissenso e hegemonia global. Petrópolis: Vozes; Brasília: NEDIC, 1999. p. 27-51.

CHAUI, M. Cultura e democracia: o discurso competente e outras falas. São Paulo: Cortez, 1989.

DIAS, R.E.; LOPES, A.C. Competências na formação de professores no Brasil: o que (não) há de novo. Educação \& Sociedade, Campinas, v. 24, n. 85 , dez. 2003. p. 1.155-1.177.

ECO, U. Apocalípticos e integrados. São Paulo: Perspectiva, 1977. 
FAIRCLOUGH, N. Discurso e mudança social. Brasília: Editora da UNB, 2001.

FONSECA, M. O Banco Mundial como referência para a justiça social no Terceiro Mundo: evidências do caso brasileiro. Revista da Faculdade de Educação, São Paulo, v. 24, n. 1, jan./jun. 1998. p. 37-69.

FREITAS, H.C.L. Certificação docente e formação do educador: regulação e desprofissionalização. Educação \& Sociedade, Campinas, v. 24, n. 85, dez. 2003. p. 1.095-1.124.

FREITAS, L.C. Neotecnicismo e formação do educador. In: Alves, N. Formação de professores: pensar e fazer. São Paulo: Cortez, 1992. p. 89102.

HOUSTON, R.W. (Org.). Exploring competency based education. California: McCutchan, 1974.

ILLICH, I. Deschooling society. Harmondsworth: Penguin, 1973.

LABARCA, G. Cuánto se puede gastar en educación? Revista de la Cepal, n. 56, ago. 1995. p. 163-178.

LEHER, R. Educação e tempos desiguais; elementos para uma reconstrução da problemática. Revista Trabalho \& Educação, Núcleo de Estudos sobre Trabalho e Educação, Universidade Federal de Minas Gerais, n. 1, fev. 1997. p. 128-142.

LEHER, R. Tempo, autonomia, sociedade civil e esfera pública: uma introdução ao debate dos novos movimentos sociais na educação. In: Gentili, P.; Frigotto, G. (Org.). A cidadania negada: políticas de exclusão na educação e no trabalho. Buenos Aires: Clacso, 2000. p. 145-176.

LÉVY, P. Cibercultura. Rio de Janeiro: Editora 34, 1999.

LIMA, K.R.S. Reforma universitária do governo Lula: o relançamento do conceito de público não-estatal. In: Neves, L.M.V. (Org). Reforma universitária no governo Lula: reflexōes para o debate. São Paulo: Xamã, 2004. p. 23-46.

MATTELART, A. História da sociedade da informação. São Paulo: Loyola, 2002. 
MÉSZÁROS, I. O século XXI: socialismo ou barbárie? São Paulo: Boitempo Editorial, 2003.

MORAN, J.M. Os novos espaços de atuação do professor com as tecnologias. In: RomAnOwsKi et al. (Org.). Conhecimento local e conhecimento universal: diversidade, mídias e tecnologias na educação. Curitiba: Champagnat, 2004. p. 245-254.

MORIN, E. Ciência com consciência. Rio de Janeiro: Bertrand Brasil, 1998.

PAPERT, S. The children's machine: rethinking school in the age of the computer. New York: Basic Books, 1993.

RAMONET, I. A tirania da comunicação. Petrópolis: Vozes, 1999.

SCHAFF, A. A sociedade informática: as conseqüências sociais da segunda revolução industrial. São Paulo: Editora da UNESP /Brasiliense, 1995.

SILVA JÚNIOR, J.R. Reformas do Estado e da educação e as políticas públicas para formação de professores a distância: implicaçôes políticas e teóricas. Revista Brasileira de Educação, n. 24, set./dez. 2003. p. 78-94.

TORRES, R.M. Tendências da formação docente nos anos 90. In: Novas Políticas Educacionais: Críticas e Perspectivas. Anais... São Paulo: Programa de Estudos Pós-Graduados em Educação: PUC, 1998. p. 173-191.

VIRILIO, P. A bomba informática. São Paulo: Estação Liberdade, 1999.

VYGOTSKY, L.V. Pensamento e linguagem. São Paulo: Martins Fontes, 1991. 